were well defined; on the front one the crystals were best developed where the stream was most active.

In accordance with the above rate of increase of deposit, namely, $\frac{3}{4}$ in. in fifteen years, 5 in. would require 100 years, $4 \mathrm{ft}$. 2 in. $\mathrm{I}, 000$, and $4 \mathrm{Ift} .8 \mathrm{in}$. 10,000 years. The data given to arrive at these results may be relied on as being accurate. In the case now related, the rate of increase of deposit was likely to continue tolerably uniform; as the surface water could have no appreciable influence in augmenting or lessening the flow from the adit.

Boltsburn, Nov. 26

JOHN CURRY

\section{Shooting-stars in the Red Sea}

ON my way to India, in November 1872 , I witnessed in the Red Sea the splendid phenomenon of a star-drift, a note about which may be of interest, in comparison with the observations at the same time in Europe.

November 24 , at 8 P.M., about 600 miles to the south of Suez, I first saw a series of shooting-stars falling from about $70^{\circ}$ W.N.W., but not in such a quantity that my attention was much attracted; I only made a note about it in my diary.

In the night of the 25th-26th I noticed nothing particular, but in that of the 26 th-27th again many shooting-stars were to be seen.

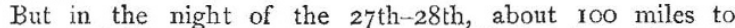
the west of Aden, the phenomenon reached its height. Through the whole night many thousands of shooting-stars were falling from every quarter of the heavens, and in all directions. It was impossible for me to count the average number falling in one minute, although I tried several times to do so, because the eye could not be everywhere, and the shooting-stars did not come from one point only. I sat the whole night on deck, to witness this sublime phenomenon of nature, which certainly was far more splendid here in the tropics than in Europe, on account of the generally greater brightness of the stars in these latitudes.

\section{A. B. Mteyer}

\section{Cuckoos}

IN vol. v. p. 383 of NATURE, you were so good as to publish a note of mine, in which I tried to describe exactly all that took place when I saw a young cuckoo throw a young pipit out of the nest.

I am much flattered to find that Mr. Gould has thought my note fit to be transferred to the introduction of his magnificent "Birds of Great Britain," and a rough sketch of mine worthy to be made the foundation of one of his large coloured plates. As, however, I have always tried in my drawings of facts in natural history to express neither more nor less than what I saw, I think it right to say that I am not the authority for many of the details in the large plate.

None of us saw the parent pipit looking on while the young cuckoo behaved so naughtily; we saw only two young pipits besides the young cuckoo, and no egg-shells. The young cuckoo was absolutely naked and blind, the young pipits partly fledged and bright eyed.

One curious point $I$ tried to call attention to in my former note in these words :- "The nest . . . . was below a heather-bush on the declivity of a low abrupt bank . . . . The most singular thing of all was the direct purpose with which the blind little monster made for the open side of the nest, the only part where it could throw its burthen down the bank." This peculiarity my rough sketch could not, and Mr. Gould's plate does not, express.

J. H. B.

$\overline{\mathrm{C}}=-\mathrm{C}$

\section{ASTRONOMICAL ALMANACS* \\ VII.-Continuation of the History of the "Nautical Almanac."}

U NTIL towards the end of the life of Maskelyne, its founder, the Nautical Almanac had the approbation of the English, and knew how to deserve the praise of foreigners; it was, according to Lalande, the most per-

\footnotetext{
* Continued from p. 70 .
}

fect ephemeris that had ever existed.* But, in 1808 , death deprived Maskelyne, who was then about 76 years of age, of his pupil and industrious collaborateur, R. Hitchins, upon whom he had depended for ten years for the most important part of his work, the verification of the calculations, and who was during that time the real editor of the Nautical Almanac. The advanced age of Maskelyne no longer permitting him to undertake any active occupation, the work passed into irresponsible hands, the calculations fell into great confusion, and "while astronomy advanced, the Nautical Almanac remained stationary, and even retrograded." + Maskelyne died shortly afterwards, in I8II, and Brown of Tiedeswill (Derbyshire), was appointed to succeed him. The new director did not improve the Nautical Almanac, and English mariners and astronomers complained loudly; a reform was necessary. The Board of Longitude being incompetent to improve the work of which it had charge, Government abolished that body in 1818 , by advice of the Admiralty, to which the publication of the work was entrusted, and which replaced the former body (which numbered sixteen members) by another much less numerous.

This new Board of Longitude was ingeniously formed ; it was composed of a Resident Committee "of three persons well versed in mathematics, astronomy, and navigation, nominated by Government," to which was added, a Commission of the Royal Society, consisting of the president and three members, charged to support it, and, if need be, to control it. The members of the resident committee had to live in London, or its neighbourhood, and to lend their aid to the Commissioners of the Royal Society for the scientific questions within the domain of the Commission. They received a salary of Iool., and the secretary of the committee, who was charged with the publication of the Nautical Almanac, a salary of $500 l$. Captain Kater, Dr. Wollaston, and Dr. Young were appointed resident members, and the latter, the secretary of the committee, had the editorship of the Nautical Almanac.

Young did much to improve the work, to restore to it the reputation for accuracy which Maskelyne had given it, and to render it capable of satisfying the constantly increasing wants of navigation. Thus, he introduced into the Almanac, in 1822, the apparent position, for every ten days, of twenty-four fundamental stars, which number was increased to sixty in 1827 ; mariners had thus constantly at their command the exact position of their reference points. Moreover, it is to him that we owe the publication of the elements by means of which we can predict occultations of stars by the moon, phenomena so useful to astronomers on an expedition, and to sailors whose ships are in a foreign harbour.

But these improvements were by no means the only ones which English astronomers and mariners demanded; as it was, the Nantical Almanac satisfied neither the one nor the other of these; sailors stood in need of the ephemerides and planetary distances of Schumacher, and astronomers of the supplement to these ephemerides. F Moreover, it often happened that these ephemerides appeared too late to be of any service to mariners who were setting out on a long voyage. Thus Young was exposed to criticism, very just, no doubt, but sometimes extremely violent. The result was an excessively sharp contrcversy, which, although sustained by most of the English

* "Correspondance astronomique francaise," of Baron de Zach, vol. iv.

pp. 87 , et seq.
Sir James South's Address to the Royal Astronomical Society, February $12,183^{\circ}$.

I The first of these ephemerides was due to the Baron de Zach, and Rear-Admiral Hövernörn caused them to be adopted by the Danish Governor in 1800 . 'The Director of Copenhagen Observatory, Thomas Bugge, was then entrusted with their editorship; they were continued by Schumacher, and a little later were published, partly at the expense of the macher, and a little later were published, pa the planets Venus, Mars, Jupiter, and Saturn for every day in the year, and their distances from the moon every three hours. 
astronomers, was concentrated in two eminent men, especially remarkable for their intense love of astronomy. The one was Sir James South, a rich landowner, who carried his love of astronomy so far as to devote the greater part of his income to the construction and main. tenance of his observatory of South Villa. The other was Francis Baily, who, by dint of his persevering efforts, got the Board of Longitude to publish, in 1825, the original observations of $\mathrm{T}$. Mayer, and who was, at a later period, the promoter of the measures taken for the publication of the numerous observations of Lalande. Behind these was the Royal Astronomical Society.

The end to be attained was as clear as it was legitimate; it was sought to make the astronomical part of the Nantical Almanac more complete and make it answer all wants. Young and the other members of the Board of Longitude opposed to these attacks a resistance unhappily too energetic. But public opinion was formed, and the first satisfaction it obtained was the suppression of the Board of Longitude in 1828 . Young was then in very bad health; indeed, it was seen that he could not live long, and it was not thought richt to sadden his last days by taking from him the direction of the Nautical Almanac.

In the meanwhile, an event of the greatest importance took place on the Continent, which rendered reforms more urgent than ever. We speak of the radical change which the illustrious Encke had introduced into the "Jahrbuch" of Berlin, a change which embodied the greater part of the desiderata named long before by Baily and Sir James South, and for which was awarded to its author the gold medal of the Astronomical Society. To comprehend this completely, it is necessary to go a little further back, and learn the history of the "Jahrbuch" from the point where we left it.

VIII.-Continuation of the History of the "Fahrbuch"

After the death of Lambert, Bode was entrusted with the care of the Fahrbuch under the direction of the Berlin Academy. But soon the difficulties which resulted from the publication of this special work, under the orders of a numerous assembly, "in which everybody had the right of criticism, but in which no one had the effective responsibility," difficulties which, during the life of Lambert, had not had time to manifest themselves, became such that in 1783 the Academy of Sciences of Berlin decided of its own accord to give up the direction of the Fahrbuch, and to leave to that member who had the actual editorship the complete responsibility as well as the honour of that publication. It was, besides, by the advice of the celebrated Lagrange that Bode was consulted. The latter then became editor of the fahrbuch, which was now published only "with the approval of the Academy."

This astronomer, however, followed religiously the plan traced by Lambert, not attempting any essential modification in the form of the fahrbuch. But in attempting to render perfect the ephemerides, he sought chiefly to collect in the second part the most remarkable astronomical results of Germany and foreign countries. For this purpose he entered into correspondence with nearly all the astronomers of Europe, and the Falirbuch of Berlin soon attained, in this respect, such a renown that, "from this time," says Lalande in his "Bibliographie Astronomique," "all astronomers are obliged to know German, for this work cannot be dispensed with." In the ephemerides the only modification of any importance on the plan of Lambert which Bode allowed himself during the whole of his editorship, was the addition of a table giving the corrections which it was necessary to make on the times of the rising and setting of the heavenly bodies at Berlin to obtain the times of the same phenomena in other latitudes.

During this time, however, astronomy had progressed.
The beautiful memoirs of Bessel on the determination of the apparent positions of the stars, the improvement made on instruments, the convenience of the methods by which Bessel had learnt to correct and revise the results of these, had increased the wants of astronomers. On the other hand, the theory of the planetary movement had made immense advances, and the planetary system itself had been enriched by four telescopic planets-Ceres (Piazzi, Jan. I, I80I), Pallas (Olbers, March 28, 1802), Juno (Harding, Sept. 1, 1804), and Vesta (Olbers, March 29 , I807). All presented the same peculiarity, that of revolving between Mars and Jupiter. It became necessary then to publish the ephemerides of these new planets, in order that astronomers might be able to observe them.

But Bode, who held for nearly half a century the astronomical sceptre of Europe, had then reached an advanced age, when the mind does not take easily to reforms.*

Bode died at Berlin, Nov. 23, 1826 . J. F. Encke, then astronomer of the Observatory of Seeberg, near Gotha, Saxony, was called to the direction of the Observatory of Berlin and of the fahrbuch.

From the first volume which he published ( $F$ ahrbuch for 1830 , May 1828), he realised all the reforms that German astronomers demanded. What then were those reforms universally called for?

\section{IX.-Programme of Reforms}

If we wish to understand them, it is enough to recall to mind that for a maritime people, ephemerides such as the Nantical Almanac and the Connaissance des Temps have a double purpose: to be serviceable to mariners and travellers, and also to astronomers, that is to say, to observatories.

At the very outset, it was evidently very useful to all that all the data of the work should be connected with the same kind of time, instead of giving for some the mean time, and for others the true time. And as astronomical tables are necessarily arranged on mean time, as on the other hand it is the most convenient for all the uses of navigation, it was good to take this mean time as the only time of the tables. It was, however, necessary to make an exception for the co-ordinates of the sun at the moment of his passage on the meridian, which, very evidently, ought to be calculated for the apparent noon or the true noon. Besides, from the purely astronomical point of view, it was evidently convenient to calculate the places of the sun, of the moon, and of the planets, with all possible precision, so that the comparison of the observations with the tables might serve to amend the latter. It was necessary then to calculate to the Iooth of a second the co-ordinates expressed in time, and to the roth those expressed in arc. On the other hand, it was necessary to give, for every day in the year, at mean noon, the geocentric (AR, and D), and heliocentric coordinates of all the principal planets, and to publish in advance ephemerides of the telescopic planets near their opposition, an epoch favourable for their observation.

Again, the observation of the eclipses of the satellites of Jupiter being one of the best means of determining the longitude of a station, it was evidently of importance that

* Johann Elhert Bode was born at Hamburg on Jan. 19, 1747. He studied under the guidance of his father, who kept a boarding-school, and at first intended him for a teacher. Mathematics, and particularly astronomy, were at an early age his favourite studies. He made his first astronomical observations in a granary, by means of a telescope which he had himself made; at $x 8$ years he knew how to calculate, with considerable precision, eclipses and the course of the planets. Some time after, Dr. Bush, with whom chance made him acquairted, lent him his books and instruments: the vocation for which he was originally destined was from that time abandoned. In 1768 he published his treatise on Astronomy, "Die Anleitung zur Kenntniss des gestirnten Himmels," which had an inmense success; shortly after he was made pensionnaire of the Berlin Academy. His most important astronomical work is his "Uranography," containing in 20 charts a list of $I 7,240$ stars, double stars, nebulæ, \&c.; i.e. 12,000 more than in the ancient charts.

$\dagger$ Encke was born at Hamburg, Sept. 23, 179r. Son of a protestant pastor, he studied under the celebrated Gauss at Göttingen; in $18 \mathrm{I}_{4}$ he was appointed by B. de Lindenau, Minister of State of Saxony, director of the Observatory of Seeberg. 
the tables of these satellites should be brought to a high degree of perfection; and as, according to the opinion of the most distinguished mathematicians, the observation of all the phenomena which are presented by one of these satellites in superior or inferior conjunction is the best means of determining certain elements of the theory of the satellites of Jupiter, it was useful to give in the collection of ephemerides not only the epochs of the eclipses, but also those of the contact of the shadow of the satellite with the planet. Tables for the observation of the satellites at the time of their maximum elongation would also be very desirable.

From the mariners' point of view, for whom the moon is the principal heavenly body, the positions of the moon calculated for noon and midnight of every day would be insufficient on account of the considerable proper movement of our satellite. To obtain the longitude of a place by means of the observation of the passage across the meridian of one of the limbs, there would be required an exce'ssively laborious calculation; the use of that method, however convenient, was then illusory. It was necessary to give the right ascension and the declination for every hour of the day, for the purpose of avoiding the employment of second differences except in cases where very great precision was sought for.

Then, when accurate tables of the movements of the planets were obtained, it was useful to add to the distances of the moon from the sun and from the stars, the distances of that body from the principal planets, the observation of which is more convenient and more certain than that of its distances from the stars.

But it was necessary to consider not only astronomers in observatories and sailors on board their ships, it was useful to enable astronomers on an expedition, and sailors when in a foreign harbour, and also geographers, to obtain the geographical co-ordinates of their station with ease and accuracy. From this point of view the method known as that of the Lunar Culminations holds the first rank, a method to which a beautiful work by Nicolaï* gave a capital importance. The learned director of the Observatory of Mannheim showed with what facility the observations of the passage of the moon combined with those of a certain number of stars, called "stars of the moon," bordering on its parallel, and passing the meridian a little before or a little after (halfan-hour at the most), could give, sufficiently approximately, the difference of the longitudes of two places, even with a meridian instrument which was not perfect. On the other hand, Bessel and Hansen had given simple methods for calculating the horary movement of the moon. To apply this method of lunar culminations, it was then necessary to choose "stars of the moon," and to publish their positions cvery year, day by day, at the same time as those of the moon at the moment of its passing the meridian. This addition had, moreover, this advantage, that by indicating by an asterisk the stars comprehended between $4^{\circ}$ and $14^{\circ}$ of declination, the observers of the two hemispheres would have the elements most useful for improving continuously (d'une façon continue) the value of the lunar parallax. The phenomenon of the occultation of the stars of the moon offers, besides, an excellent means of determining longitudes. It was then important thus to calculate in advance and to publish all the elements likely to serve for predicting all the occultations in a given place, for the purpose of rendering the employment of this method easy to the navigator.

Finally it was indispensable, as well for the astronomical operations of observatories as for those connected with an astronomical or a geodetic expedition, that the collection of ephemerides should contain, for epochs sufficiently close to permit calculation for intermediate dates

* "Uber die Methocle, längen durch Rectascensions-Differenzen gewählten Vergleichsterne vom Monde zu bestimmen" (Astronomische wählten Vergleichsterne vom
Nachrichten for 1823 and 1824 .) by simple proportion, the apparent positions of a very large number of stars of the greatest magnitude, and distributed both in the north and south hemispheres. It was useful, moreover, to join to this catalogue the values for very close epochs of the constants of Bessel, which enable one to pass from the mean position of a star at the commencement of the year to its apparent position on any day whatever.

For the principal circumpolars, $a$ and $\delta$ Ursæ Minoris, the importance of which is so great in determining the various constants of a meridian instrument, and whose apparent positions vary much more rapidly than those of stars at a distance from the pole,-the apparent positions ought to be given every day.

Such is, with the exception of a few unimportant details, the list of reforms which the general opinion of astronomers demanded in England and Germany.

(To be continued.)

\section{ON THE SECONDARY WAVES IN THE SPHYGMOGRAPH TRACE}

$\mathrm{N}$ a letter printed in this journal a short time ago (vol. viii. p. 464), Dr. Galabin refers to a paper which has been since published in the Fournal of Anatomy and Physiology (No. XII. p. I), for a fuller account of his views as to the theory of the pulse, of which we gave a short notice and criticism in a former number (vol. viii. p. 330). This second and more detailed description calls for further remark, especially as the author has found reason somewhat to modify his opinion on one important point.

As is well known, the sphygmograph trace of a pulse beat (see Fig. I) consists of a primary rapid rise, followed by a more gxadual fall, broken by a considerable undulation, termed the dicrotic wave, which varies in its distance from the next primary rise according to the rapidity of the pulse. Between the primary and the dicrotic rises in the trace, the descending curve is sometimes interrupted by another small undulation termed the "tidal" wave, by Mr. Mahomed, though the name predicrotic is better, as it does not involve any theoretical conceptions. It is the development in the trace of these predicrotic and dicrotic waves that Dr. Galabin discusses and his explanation of the former is the fol lowing.-The separation of the primary and tidal (predicrotic) waves is due to an oscillation in the Sphygmograph, caused by the inertia of the instrument. In some cases the lever may be separated slightly from the knife-edge on which it rests, but generally the oscillation takes place in the instrument as a whole, and it may be followed by others in a descending series. With reference to this interpretation, it may be first remarked that it seems almost impossible that the whole sphygmograph should acquire a momentum in each pulsation, for it should be so adjusted on the arm that no part except the tip of the spring is in any way in contact with the artery, and when such is the case it is difficult to conceive of any shock being communicated to the whole. Again, any sudden upward impulse given to the instrument itself would be attended with a descent in the trace, for as the lever is only attached at one end, and there only on points, its pen would be slow to participate in the general movement of the framework, and would not rise so rapidly as the recording paper. The momentum acquired by the lever is a different thing. Marey and Sanderson have both shown that the primary rise in the trace may be attended with a sudden sharppoinied wave, in the production of which the lever leaves the knife-edge on which it rests, returning to it after a very short excursion. To prevent the excessive development of this imperfection Marey has employed a small secondary spring to depress the lever; this spring Dr. 